\title{
Comparative risks of chronic inhaled corticosteroids and macrolides for bronchiectasis
}

\author{
Emily Henkle (1) ${ }^{1}$, Jeffrey R. Curtis², Lang Chen², Benjamin Chan', \\ Timothy R. Aksamit ${ }^{3}$, Charles L. Daley ${ }^{4}$, David E. Griffith ${ }^{5}$ and \\ Kevin L. Winthrop ${ }^{1}$
}

Affiliations: ${ }^{1}$ OHSU-PSU School of Public Health, Oregon Health and Science University, Portland, OR, USA. ${ }^{2}$ Division of Clinical Immunology and Rheumatology, University of Alabama at Birmingham, Birmingham, AL, USA. ${ }^{3}$ Pulmonary Disease and Critical Care Medicine, Mayo Clinic, Rochester, MN, USA. ${ }^{4}$ Division of Mycobacterial and Respiratory Infections, National Jewish Health, Denver, CO, USA. ${ }^{5}$ Pulmonary Infectious Disease Section, University of Texas Health Science University, Tyler, TX, USA.

Correspondence: Emily Henkle, OHSU-PSU School of Public Health, Oregon Health and Science University, 3181 SW Sam Jackson Park Road, Mailcode GH104, Portland, OR 97239, USA. E-mail henkledohsu.edu

@ERSpublications

Macrolides are a better choice than ICSs to prevent hospitalised respiratory infections in older bronchiectasis patients, but the safety and long-term effects of chronic macrolide use need to be further evaluated http://ow.ly/1SOV30o8eLs

Cite this article as: Henkle E, Curtis JR, Chen L, et al. Comparative risks of chronic inhaled corticosteroids and macrolides for bronchiectasis. Eur Respir J 2019; 54: 1801896 [https://doi.org/10.1183/13993003.018962018].

\section{ABSTRACT}

Introduction: Non-cystic fibrosis (CF) bronchiectasis ("bronchiectasis") is a chronic airway disease for which little data exist to inform treatment decisions. We sought to compare the risks of respiratory infections in chronic users of inhaled corticosteroids (ICSs) versus macrolide monotherapy.

Methods: We identified a cohort of US Medicare enrollees with a bronchiectasis diagnosis (International Classification of Diseases, Ninth Revision, Clinical Modification code 494.0 or 494.1) between 2006 and 2014, excluding CF. We defined chronic new use as the first $\geqslant 28$-day prescription of ICS therapy or macrolide monotherapy. We compared the characteristics of the exposure cohorts using standardised mean differences (SMDs) and computed a propensity score (PS) to account for treatment differences. The risks of acute exacerbation, hospitalised respiratory infection, all-cause hospitalisation and mortality were compared using PS decile-adjusted Cox regression models.

Results: We identified 83589 new users of ICSs and 6500 new users of macrolides from 285043 included Medicare enrollees with bronchiectasis. The crude incidence of hospitalised respiratory infection was 12.6 (ICS therapy) and 10.3 (macrolide monotherapy) per 100 patient-years. The PS-adjusted HRs comparing ICS with macrolide new users were 1.39 (95\% CI 1.23-1.57) for hospitalised respiratory infection, 1.56 (95\% 1.49-1.64) for acute exacerbation and 1.09 (95\% 0.95-1.25) for mortality.

Interpretation: Among patients with bronchiectasis, the use of ICSs was associated with an increased risk of hospitalised respiratory infections compared with macrolide monotherapy. 


\section{Introduction}

Non-cystic fibrosis (CF) bronchiectasis ("bronchiectasis") is an increasingly common, chronic airway disease $[1,2]$. The disease is characterised by bronchial inflammation and chronic cough, with frequent exacerbations, i.e. increased symptoms, occurring in the majority of patients $[3,4]$. Chronic infection with Pseudomonas aeruginosa, advanced disease severity and multimorbidity all increase the risk for hospitalisation and death among bronchiectasis patients [5-7]. Additional risk factors for frequent exacerbations include older age, smoking history, comorbidities such as chronic obstructive pulmonary disease (COPD) and heart disease, and bronchiectasis disease severity [8].

At present, pharmacological strategies are commonly employed to treat bronchiectasis, yet very little effectiveness or safety data exist to guide patient-centred decision making. One of the primary goals of bronchiectasis treatment is to reduce airway inflammation and prevent exacerbations that lead to hospitalisation. In recent years several expert-based guidelines that describe pharmacotherapy options have been published [9-11]. Options that have been reviewed include oral corticosteroids (OCSs) or inhaled corticosteroids (ICSs), oral or inhaled antibiotics and techniques to promote airway hygiene/mucous clearance.

To the best of our knowledge, there are no long-term studies specifically evaluating the risks or potential benefits of OCSs or ICSs in bronchiectasis patients, although the risk of pneumonia is increased in patients with COPD taking ICSs [12]. ICSs are also associated with an increased risk of nontuberculous mycobacteria (NTM) infection in patients with COPD [13]. Corticosteroids are often prescribed short-term to treat bronchiectasis exacerbations, but are also frequently prescribed chronically in an attempt to limit inflammation and slow bronchiectasis progression [14]. Despite common use of ICSs in this patient population, none of the published bronchiectasis treatment guidelines have recommended the use of ICSs in bronchiectasis patients due to the lack of evidence, except as indicated to treat concomitant asthma or COPD [9-11].

In contrast, there is some limited evidence that long-term use of antibiotics benefits patients with bronchiectasis. One mechanism for improving outcomes is the reduction in bacterial load and associated inflammation. In addition, macrolides (erythromycin and azithromycin) are oral antibiotics that also exhibit immunomodulatory effects that may reduce the airway inflammation associated with bronchiectasis patients [15]. They have been tested in three small randomised trials that used exacerbations as a primary end-point, with macrolide-treated groups experiencing fewer respiratory exacerbations over the 6-12-month study period [16-18]. The most recent bronchiectasis treatment guidelines recommend macrolides in patients with a recent history of multiple exacerbations, with the European guidelines suggesting macrolides after inhaled antibiotics are contraindicated, not tolerated or fail to reduce exacerbations in those with a $P$. aeruginosa infection $[10,11]$.

Accordingly, we compared outcomes of two anti-inflammatory therapies, i.e. ICS therapy and macrolide monotherapy, in bronchiectasis patients using a robust new-user observational cohort design [19]. We evaluated the relative risks of hospitalised respiratory infection, all-cause hospitalisation and mortality in older bronchiectasis patients using a large cohort identified from US Centers for Medicare and Medicaid Services (Medicare) enrollees.

\section{Methods}

\section{Data source and cohort eligibility}

Medicare provides insurance to all adults aged $\geqslant 65$ years and some people with disabilities in the USA. We obtained a dataset of all patients with an International Classification of Diseases, Ninth Revision, Clinical Modification (ICD-9-CM) code for bronchiectasis (494.0 or 494.1) from Medicare Parts A, B and D (but not C) during 2006-2014. Medicare Part A includes all inpatient claims, Part B includes all outpatient claims and Part D includes all prescription drug claims for patients who do not have Part C (Medicare Advantage). The bronchiectasis codes have not been previously validated, but have been used in earlier epidemiological studies in Medicare data [20,21]. Our bronchiectasis cohort was further restricted to those with the bronchiectasis diagnosis code from a pulmonologist and excluded those who ever had a diagnosis of CF, HIV infection or history of organ transplant.

\section{Exposure}

Our exposures were ICS therapy or macrolide monotherapy. We used a new-user cohort design, with established methodology previously described [19, 22-24]. New use was defined as the first prescription for a minimum 28-day ("chronic") supply of either of the exposures of interest, after a clean period of 12 months. The clean period was defined as without a prescription for $\geqslant 28$ days of either exposure of interest. ICS therapy included ICS alone or in combination with long-acting $\beta$-agonists, and macrolide monotherapy was defined as oral azithromycin or erythromycin and no other chronic prescription within 
30 days that could be associated with NTM therapy (ethambutol, a rifamycin or a fluoroquinolone). Patients who did not start on macrolide monotherapy were excluded.

\section{Outcomes}

The primary outcome of interest was hospitalised respiratory infection, and secondary outcomes included all-cause (with and without respiratory infection) hospitalisation, all-cause mortality and acute exacerbation. We defined hospitalised respiratory infection as an inpatient visit with a principal diagnosis of ICD-9-CM 480-487.0 [25, 26] or a bronchiectasis exacerbation (ICD-9-CM 494.1). We defined acute exacerbations as treatment presumed to be for an acute respiratory infection: a 7-28-day supply of erythromycin, clarithromycin, levofloxacin, moxifloxacin, ciprofloxacin, minocycline, trimethoprim/sulfamethoxazole, amoxicillin, amoxicillin/ clavulanate or doxycycline, or a 3-28-day supply of azithromycin that was not associated with wound or stool culture or urinalysis. As a sensitivity analysis we also evaluated acute exacerbations with this definition and ICD-9-CM 494.1 diagnostic code in any setting \pm 7 days from the diagnosis.

\section{Ethical approval}

The Oregon Health and Science University (Portland, OR, USA) and University of Alabama at Birmingham (Birmingham, AL, USA) institutional review boards approved the study protocol.

\section{Statistical analysis}

Exposure cohort characteristics were compared using standardised mean differences (SMDs). SMDs $>0.10$ were considered imbalanced [27]. Follow-up began at the time of drug initiation of either drug exposure group and ended at the first occurrence of the outcome of interest, loss of medical and pharmacy coverage, death, the end of the data or end of drug exposure plus a 30-day extension. Patients who added the comparison drug or switched exposure groups were censored at the time of new prescription. We calculated the crude incidence rate as incident events divided by the total person-years for each exposed group.

For each patient, we calculated a propensity score (PS) in a logistic regression model using the baseline demographic, comorbidity and utilisation history variables listed in table 1 . This model estimated the probability a patient receives therapy with ICS (versus macrolide therapy). PS scores by exposure cohorts were reviewed for overlapping distributions, dropping patients with nonoverlapping PS [19]. The PS was grouped into deciles based on the PS in the macrolide monotherapy group [28]. Key covariates were plotted by decile to check for balance between exposure cohorts. We used Cox proportional hazard regression models to compare incidence of outcomes between new users of ICSs and macrolides, adjusted for PS decile category and OCS use category, a pre-specified potential confounder [29]. We conducted sensitivity analyses of the outcomes models using weighted and/or truncated PS and separately after trimming the tails to $2.5 \%$ on either end. Additional sensitivity analysis stratified results by sex, COPD, asthma diagnosis and prior NTM history. We defined a priori that a $25 \%$ increase (i.e. HR 1.25) is a clinically meaningful increase in the risk of a given outcome (hospitalisation, death, etc.). All analyses were done in SAS version 9.4 (SAS Institute, Cary, NC, USA).

\section{Results}

We received data from Medicare for 618303 patients with a bronchiectasis diagnosis. Of these, 285043 (46.1\%) met our eligibility criteria (figure 1). We further identified and described 83589 (29.3\%) ICS therapy and $6500(2.3 \%)$ macrolide monotherapy new users (table 1). Patients in the two exposure cohorts were similar with regard to age (mean 74.4 years ICS versus 74.8 years macrolide; SMD 0.04 ), but patients taking ICSs were less likely female (67.7\% versus $73.1 \%$; SMD 0.12 ) and White (non-Hispanic) $(82.0 \%$ versus $89.5 \%$; SMD 0.23) compared with those taking macrolides. Baseline history of inpatient admissions and hospitalised respiratory infections was similar (SMD 0.08 and 0.07 , respectively), but notable differences in baseline healthcare utilisation history were observed, e.g. fewer baseline pulmonologist encounters (SMD 0.44) and acute respiratory infections in the ICS cohort (SMD 0.33). The ICS cohort was less likely to have a prior diagnosis of Pseudomonas infection (6.1\% versus $12.5 \%$ of macrolide cohort; SMD 0.22) and NTM infection (3.8\% versus 20.1\%; SMD 0.52), and more likely to have a COPD/ emphysema diagnosis (84.4\% versus $77.7 \%$; SMD 0.17).

The crude incidence rates of hospitalised respiratory infection (table 2) were 12.6 (95\% CI 12.3-13.0) per 100 patient-years for the ICS cohort and 10.3 (95\% CI 9.2-11.5) per 100 patient-years for the macrolide cohort. The rates for other outcomes ranged from 6.2 (mortality) to 104.2 (acute exacerbation) per 100 patient-years for the ICS cohort and 5.8 (mortality) to 72.9 (acute exacerbation) per 100 patient-years for the macrolide cohort.

The PS model included all characteristics in table 1. The overlap and decile cut-points are shown in supplementary figure S1. The area under the receiver operating characteristic curve was 0.76. Key PS 
TABLE 1 Characteristics of US Medicare bronchiectasis new users of inhaled corticosteroid (ICS) therapy or macrolide monotherapy

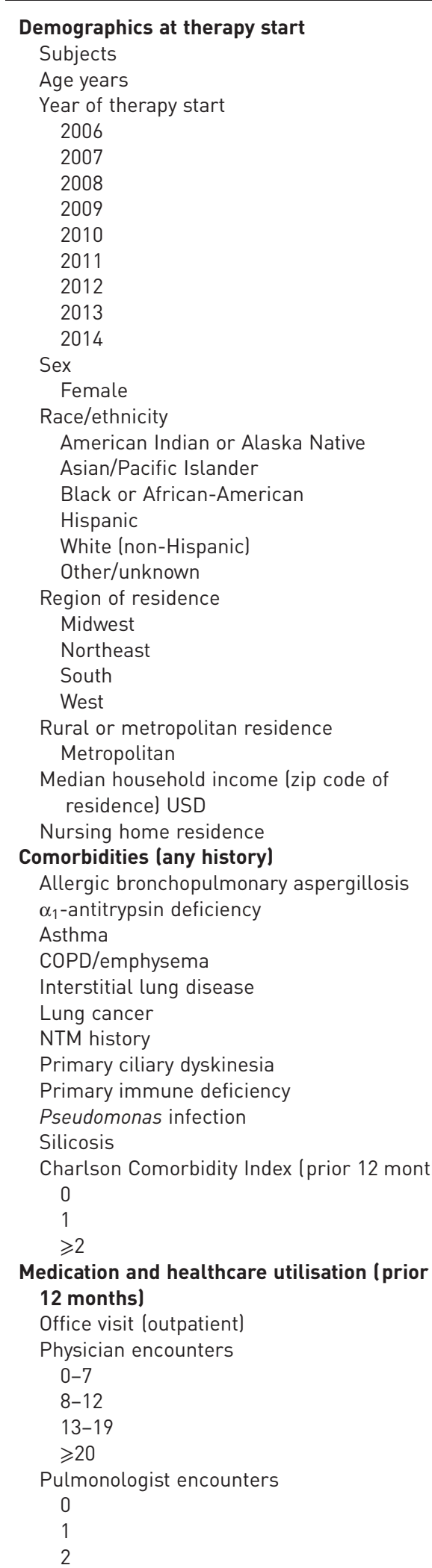

ICS therapy

Macrolide monotherapy

SMD

83589
$74.42 \pm 10.18$
$7326(8.8)$
$6374(7.6)$
$6753(8.1)$
$7949(9.5)$
$8260(9.9)$
$8976(10.7)$
$10721(12.8)$
$15991(19.1)$
$11239(13.4)$

$56583(67.7)$

$362(0.4)$
$3353(4.0)$
$5338(6.4)$
$5188(6.2)$
$68508(82.0)$
$840(1.0)$

17129 (20.5)

$18629(22.3)$

33289 (39.8)

$14542(17.4)$

$65261(78.1)$

$59210 \pm 25500$

$8408(10.1)$

854 (1.0)

$292(0.3)$

$33480(40.1)$

$70548(84.4)$

$5526(6.6)$

$3497(4.2)$

$3164(3.8)$

$141(0.2)$

$3857(4.6)$

$5123(6.1)$

$103(0.1)$

20514 (24.5)

33959 (40.6)

29116 (34.8)

81073 (97.0)

24345 (29.1)

20027 (24.0)

20549 (24.6)

18668 (22.3)

19013 (22.7)

15157 (18.1)

$15437(18.5)$

$$
\begin{gathered}
6500 \\
74.82 \pm 10.11 \\
429(6.6) \\
339(5.2) \\
483(7.4) \\
523(8.0) \\
570(8.8) \\
782(12.0) \\
978(15.0) \\
1275(19.6) \\
1121(17.2) \\
\\
4750(73.1) \\
17(0.3) \\
160(2.5) \\
236(3.6) \\
203(3.1) \\
5820(89.5) \\
64(1.0)
\end{gathered}
$$

1612 (24.8)

$992(15.3)$

$2897(44.6)$

999 (15.4)

4798 (73.8)

$59490 \pm 25220$

$470(7.2)$

64 (1.0)

$43(0.7)$

$1795(27.6)$

5050 (77.7)

507 (7.8)

196 (3.0)

1307 (20.1)

$23(0.4)$

$466(7.2)$

810 (12.5)

$6(0.1)$

1534 (23.6)

$3119(48.0)$

1847 (28.4)

6365 (97.9)

1482 (22.8)

1526 (23.5)

1771 (27.2)

1721 (26.5)

$692(10.6)$

941 (14.5)

1032 (15.9)$$
0.12^{\#}
$$

0.10

0.01

0.10

0.00

0.06

$0.16^{\#}$

0.04

$0.19^{\#}$

$0.23^{\#}$

$0.21^{\#}$

0.04

$0.27^{\#}$

$0.17^{\#}$

0.05

0.06

$0.52^{\#}$

0.04

$0.11^{\#}$

$0.22^{\#}$

0.01

$0.16^{\#}$

$0.44^{\#}$ 


\begin{tabular}{|c|c|c|c|}
\hline & ICS therapy & Macrolide monotherapy & SMD \\
\hline 3 & $11025(13.2)$ & 1005 (15.5) & \\
\hline 4 & $7232(8.7)$ & $724(11.1)$ & \\
\hline$\geqslant 5$ & 15725 (18.8) & $2106(32.4)$ & \\
\hline \multicolumn{4}{|l|}{ Inpatient admissions } \\
\hline 1 & $17943(21.5)$ & $1299(20.0)$ & \multirow[t]{2}{*}{0.08} \\
\hline$\geqslant 2$ & $15851(19.0)$ & $1093(16.8)$ & \\
\hline \multicolumn{4}{|l|}{ Hospitalised respiratory infections } \\
\hline$\geqslant 1$ & $9583(11.5)$ & $885(13.6)$ & 0.07 \\
\hline \multicolumn{4}{|l|}{ Acute respiratory infections } \\
\hline 0 & $40746(48.7)$ & $2478(38.1)$ & \multirow[t]{4}{*}{$0.33^{\#}$} \\
\hline 1 & $20193(24.2)$ & $1384(21.3)$ & \\
\hline $2-3$ & $15993(19.1)$ & $1499(23.1)$ & \\
\hline$\geqslant 4$ & $6657(8.0)$ & $1139(17.5)$ & \\
\hline \multicolumn{4}{|l|}{ Distinct medication classes } \\
\hline $1-8$ & $24768(29.6)$ & $2169(33.4)$ & \multirow[t]{4}{*}{$0.12^{\#}$} \\
\hline $9-12$ & $18871(22.6)$ & $1540(23.7)$ & \\
\hline $13-17$ & $19182(22.9)$ & $1478(22.7)$ & \\
\hline$\geqslant 18$ & $20768(24.8)$ & $1313(20.2)$ & \\
\hline \multicolumn{4}{|c|}{ Mean prednisone-equivalent dose category } \\
\hline No oral corticosteroid & $50227(60.1)$ & 4077 (62.7) & \multirow[t]{5}{*}{$0.16^{\#}$} \\
\hline Low $\left(<2.5 \mathrm{mg} \cdot \mathrm{day}^{-1}\right)$ & $25572(30.6)$ & $1614(24.8)$ & \\
\hline Medium-low (2.5-5 mg.day ${ }^{-1}$ ) & $4226(5.1)$ & $358(5.5)$ & \\
\hline Medium-high $\left(5-10 \mathrm{mg} \cdot\right.$ day $\left.^{-1}\right)$ & $2739(3.3)$ & $343(5.3)$ & \\
\hline High ( $\geqslant 10 \mathrm{mg} \cdot$ day $^{-1}$ ) & $825(1.0)$ & $108(1.7)$ & \\
\hline Nebuliser & 31502 (37.7) & $2681(41.2)$ & 0.07 \\
\hline Home oxygen & $26810(32.1)$ & $1934(29.8)$ & 0.05 \\
\hline
\end{tabular}

Data are presented as $\mathrm{n}$, mean \pm SD or $\mathrm{n}(\%)$, unless otherwise stated. SMD: standardised mean difference; COPD: chronic obstructive pulmonary disease; NTM: nontuberculous mycobacteria. ${ }^{\#}$ : SMDs $>0.10$ were considered imbalanced.

FIGURE 1 Selection of bronchiectasis cohorts of clean new users of chronic inhaled corticosteroid (ICS) therapy and macrolide monotherapy. ICD-9-CM: International Classification of Diseases, Ninth Revision, Clinical Modification.
At least one

ICD-9-CM 494.0 or 494.1 claim ( $\mathrm{n}=618303$ )

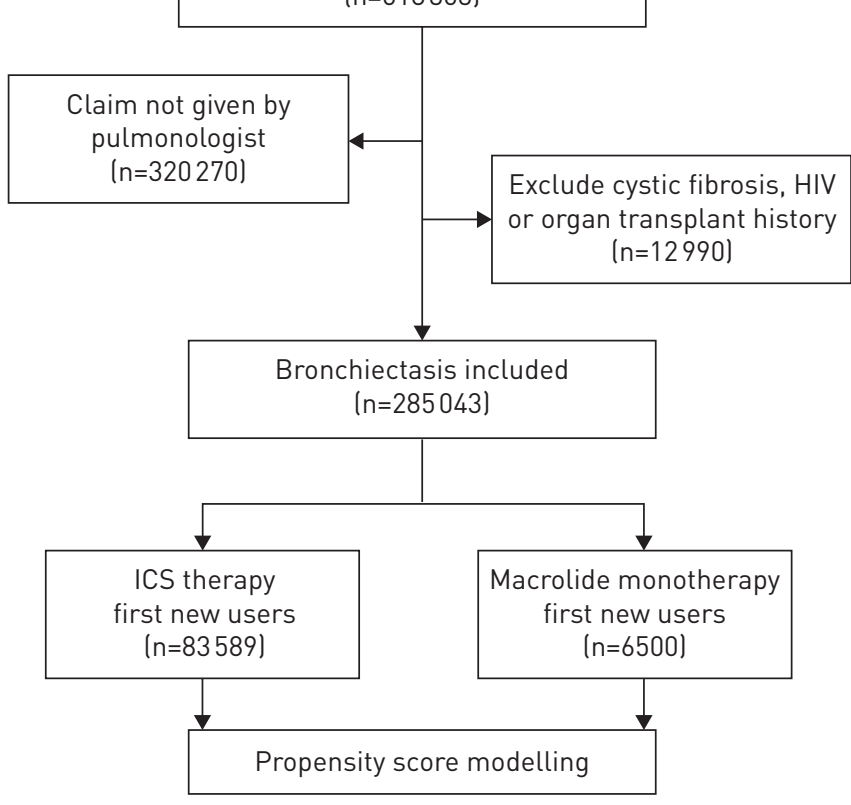


TABLE 2 Incident rates of acute exacerbation, hospitalised respiratory infection, all-cause (except respiratory infection) hospitalisation, all-cause hospitalisation and mortality among new users of chronic inhaled corticosteroid (ICS) therapy and macrolide monotherapy with bronchiectasis

\begin{tabular}{|c|c|c|c|c|c|c|}
\hline \multirow[t]{2}{*}{ Outcome } & \multicolumn{3}{|c|}{ ICS therapy } & \multicolumn{3}{|c|}{ Macrolide monotherapy } \\
\hline & Events $\mathbf{n}$ & Patient-years & $\begin{array}{l}\text { Incidence rate } \\
(95 \% \mathrm{Cl})^{\#}\end{array}$ & Events $\mathbf{n}$ & Patient-years & $\begin{array}{l}\text { Incidence rate } \\
\qquad(95 \% \mathrm{CI})^{\#}\end{array}$ \\
\hline Hospitalised respiratory infection & 4213 & 33328 & $12.6(12.3-13.0)$ & 317 & 3068 & $10.3(9.2-11.5)$ \\
\hline $\begin{array}{l}\text { All-cause lexcept respiratory } \\
\text { infection) hospitalisation }\end{array}$ & 15611 & 29785 & $52.4(51.6-53.2)$ & 1177 & 2808 & $41.9(39.6-44.4)$ \\
\hline
\end{tabular}

\#: incidence rate per 100 patient-years.

model covariates were balanced across treatment group within each decile (supplemental figures), indicating the PS model adequately controlled for treatment exposure differences. The one exception was prior NTM history (supplementary figure S2a), which exhibited imbalance in the lowest PS decile. We subsequently included this as a covariate in the Cox proportional hazards models for all outcomes.

The unadjusted and PS-adjusted hazard ratios comparing the use of ICS to macrolide monotherapy are shown in figure 2. All hazard ratios were statistically significant, except for mortality. The adjusted HRs were 1.39 (95\% CI 1.23-1.57) for hospitalised respiratory infection and 1.56 (95\% CI 1.49-1.64) for acute exacerbation. Mortality was not increased (adjusted HR 1.09 (95\% CI 0.95-1.25)).

The primary diagnosis groups associated with hospitalisation and death are listed in table 3. For hospitalised respiratory infection, the ranking of the top 10 leading causes was very similar, but the proportion related to the top diagnoses varied: the ICS and macrolide cohorts were hospitalised due to pneumonia, organism unspecified (60.3\% and $44.5 \%)$, bronchiectasis exacerbation $(13.2 \%$ and $27.4 \%)$ and pseudomonal pneumonia (9.7\% and $13.2 \%)$. The leading cause of all-cause (except respiratory infection) hospitalisation was COPD exacerbation (11.7\% of ICS cohort and $8.8 \%$ of macrolide cohort), with septicaemia occurring as the second most common diagnosis (5.0\% and $4.4 \%$, respectively). The leading causes of death during or proximal to hospitalisations for the ICS cohort were septicaemia $(8.5 \%)$, pneumonia $(6.1 \%)$ and acute respiratory failure (4.7\%), and for the macrolide cohort acute and chronic respiratory failure (7.0\%), septicaemia (6.7\%), and acute respiratory failure (5.6\%).

Sensitivity analysis using weighted and/or truncated PS and trimming the tails by $2.5 \%$ produced similar results in both the direction and strength of effect (data not shown). Stratification by sex and COPD

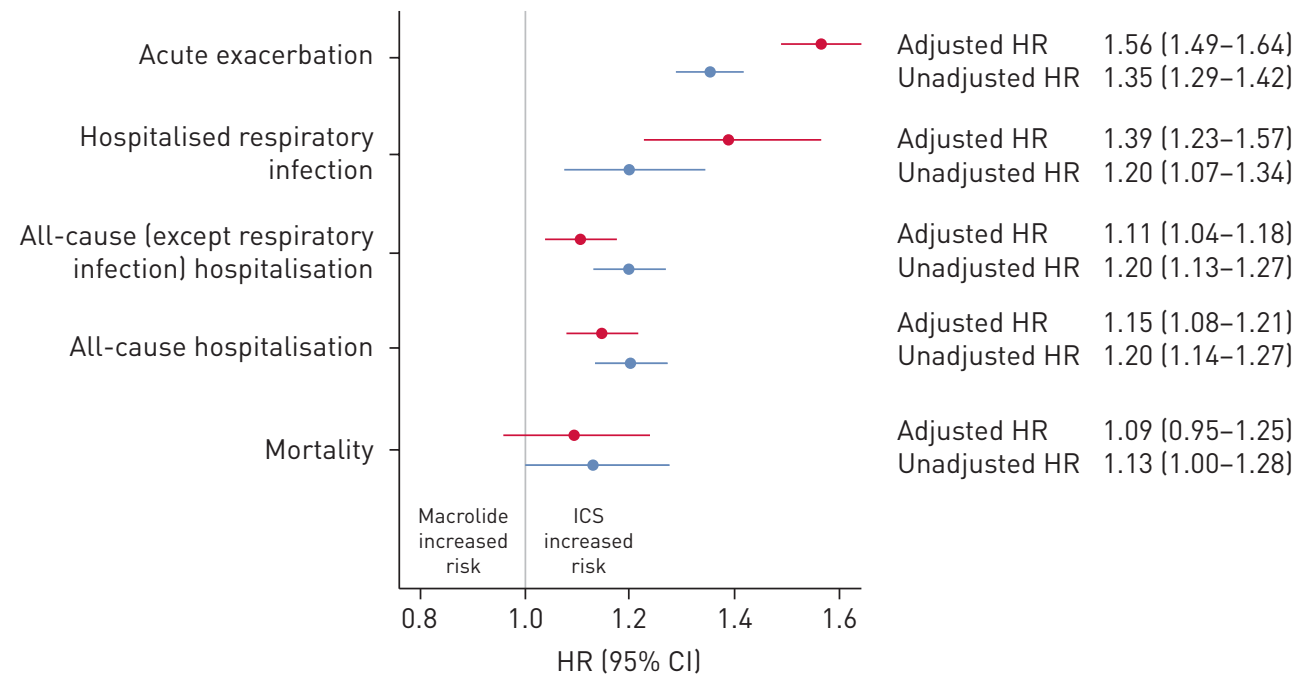

FIGURE 2 Forest plot of unadjusted (blue) and adjusted (red) hazard ratios (95\% Cls) of key outcomes comparing new use of inhaled corticosteroid (ICS) therapy to macrolide monotherapy for bronchiectasis. Adjusted hazard ratios included propensity score decile, oral corticosteroid dose category and nontuberculous mycobacteria history. 
TABLE 3 The most common primary diagnoses associated with inpatient hospitalisation and hospital-associated deaths

\begin{tabular}{|c|c|c|c|c|c|}
\hline \multicolumn{2}{|c|}{ Hospitalised respiratory infection } & \multicolumn{2}{|c|}{ All-cause (except respiratory infection) hospitalisation } & \multicolumn{2}{|c|}{ Death at hospital or within 30 days of discharge } \\
\hline $\begin{array}{l}\text { ICS therapy } \\
(n=4213)^{\pi 1}\end{array}$ & $\begin{array}{l}\text { Macrolide monotherapy } \\
\qquad(\mathrm{n}=317)^{\pi}\end{array}$ & $\begin{array}{l}\text { ICS therapy } \\
(\mathrm{n}=15611)^{\pi}\end{array}$ & $\begin{array}{l}\text { Macrolide monotherapy } \\
\qquad(\mathrm{n}=1177)^{\pi}\end{array}$ & $\begin{array}{l}\text { ICS therapy } \\
(n=2235)^{\pi}\end{array}$ & $\begin{array}{l}\text { Macrolide monotherapy } \\
\qquad(n=185)^{\pi}\end{array}$ \\
\hline 486 Pneumonia (60.3\%) & 486 Pneumonia $(44.5 \%)$ & $\begin{array}{c}491.21 \text { COPD exacerbation } \\
(11.7 \%)\end{array}$ & $\begin{array}{c}491.21 \text { COPD exacerbation } \\
(8.8 \%)\end{array}$ & 038.9 Septicaemia (8.5\%) & $\begin{array}{l}518.84 \text { Acute and chronic } \\
\text { respiratory failure }(7.0 \%)\end{array}$ \\
\hline $\begin{array}{l}\text { 494.1 Bronchiectasis } \\
\text { exacerbation (13.2\%) }\end{array}$ & $\begin{array}{l}\text { 494.1 Bronchiectasis } \\
\text { exacerbation }(27.4 \%)\end{array}$ & 038.9 Septicaemia (5.0\%) & 038.9 Septicaemia $(4.4 \%)$ & 486 Pneumonia $(6.1 \%)$ & 038.9 Septicaemia $(6.7 \%)$ \\
\hline $\begin{array}{l}482.1 \text { Pseudomonal } \\
\text { pneumonia }(9.7 \%)\end{array}$ & $\begin{array}{l}\text { 482.1 Pseudomonal } \\
\text { pneumonia }(13.2 \%)\end{array}$ & $\begin{array}{l}\text { 491.22 COPD with acute } \\
\text { bronchitis }(2.9 \%)\end{array}$ & $\begin{array}{l}518.84 \text { Acute and chronic } \\
\text { respiratory failure }(3.4 \%)\end{array}$ & $\begin{array}{l}518.81 \text { Acute respiratory } \\
\text { failure }(4.7 \%)\end{array}$ & $\begin{array}{l}518.81 \text { Acute respiratory } \\
\text { failure }(5.6 \%)\end{array}$ \\
\hline $\begin{array}{c}\text { 482.83 Pneumonia, } \\
\text { Gram-negative bacteria } \\
(3.0 \%)\end{array}$ & $\begin{array}{c}\text { 482.83 Pneumonia, } \\
\text { Gram-negative bacteria } \\
(2.8 \%)\end{array}$ & $\begin{array}{l}518.84 \text { Acute and chronic } \\
\text { respiratory failure }(2.9 \%)\end{array}$ & $\begin{array}{l}491.22 \text { COPD with acute } \\
\text { bronchitis (3.1\%) }\end{array}$ & $\begin{array}{l}518.84 \text { Acute and chronic } \\
\text { respiratory failure }(4.5 \%)\end{array}$ & $\begin{array}{c}491.21 \text { COPD exacerbation } \\
\text { (4.1\%) }\end{array}$ \\
\hline $\begin{array}{c}\text { 482.42 MRSA pneumonia } \\
(2.5 \%)\end{array}$ & $\begin{array}{c}482.9 \text { Bacterial pneumonia } \\
(2.2 \%)\end{array}$ & $\begin{array}{l}518.81 \text { Acute respiratory } \\
\text { failure }(2.6 \%)\end{array}$ & $\begin{array}{l}\text { 427.31 Atrial fibrillation } \\
(2.6 \%)\end{array}$ & $\begin{array}{l}491.21 \text { COPD exacerbation } \\
(4.5 \%)\end{array}$ & 486 Pneumonia $(3.7 \%)$ \\
\hline $\begin{array}{c}\text { 482.41 MSSA pneumonia } \\
(1.9 \%)\end{array}$ & $\begin{array}{c}\text { 482.42 MRSA pneumonia } \\
(1.9 \%)\end{array}$ & $\begin{array}{c}\text { 493.22 Chronic obstructive } \\
\text { asthma exacerbation } \\
(2.5 \%)\end{array}$ & $\begin{array}{l}518.81 \text { Acute respiratory } \\
\text { failure }(2.5 \%)\end{array}$ & $\begin{array}{c}507.0 \text { Food/vomit pneumonitis } \\
(3.1 \%)\end{array}$ & $\begin{array}{l}507.0 \mathrm{Food} / \text { vomit } \\
\text { pneumonitis }(2.2 \%)\end{array}$ \\
\hline $\begin{array}{c}482.9 \text { Bacterial pneumonia } \\
(1.9 \%)\end{array}$ & $\begin{array}{l}\text { 482.41 MSSA pneumonia } \\
(1.6 \%)\end{array}$ & $\begin{array}{l}507.0 \text { Food/vomit } \\
\text { pneumonitis }(2.3 \%)\end{array}$ & $\begin{array}{l}507.0 \mathrm{Food} / \text { vomit } \\
\text { pneumonitis }(2.3 \%)\end{array}$ & $\begin{array}{l}515 \text { Post-inflammatory } \\
\text { pulmonary fibrosis }(1.6 \%)\end{array}$ & $\begin{array}{l}482.1 \text { Pseudomonal } \\
\text { pneumonia }(1.9 \%)\end{array}$ \\
\hline $\begin{array}{l}481 \text { Pneumococcal } \\
\text { pneumonia (1.6\%) }\end{array}$ & $\begin{array}{l}481 \text { Pneumococcal } \\
\text { pneumonia }(0.9 \%)\end{array}$ & $\begin{array}{c}\text { 427.31 Atrial fibrillation } \\
(2.1 \%)\end{array}$ & $\begin{array}{l}\text { 493.22 Chronic obstructive } \\
\text { asthma exacerbation (1.8\%) }\end{array}$ & $\begin{array}{c}\text { 428.0 Congestive heart failure } \\
(1.0 \%)\end{array}$ & $\begin{array}{l}515 \text { Post-inflammatory } \\
\text { pulmonary fibrosis (1.9\%) }\end{array}$ \\
\hline $\begin{array}{c}485 \text { Bronchopneumonia } \\
(1.0 \%)\end{array}$ & $\begin{array}{l}485 \text { Bronchopneumonia } \\
(0.9 \%)\end{array}$ & $\begin{array}{l}428.0 \text { Congestive heart } \\
\text { failure }(1.8 \%)\end{array}$ & $\begin{array}{l}584.9 \text { Acute kidney failure } \\
(1.4 \%)\end{array}$ & $\begin{array}{l}410.71 \text { Subendocardial } \\
\text { infarction, initial }(0.9 \%)\end{array}$ & $\begin{array}{l}820.21 \text { Intertrochanteric } \\
\text { fracture }(1.1 \%)\end{array}$ \\
\hline $\begin{array}{l}487.0 \text { Influenza with } \\
\text { pneumonia }(0.8 \%)\end{array}$ & $\begin{array}{l}482.0 \text { Klebsiella pneumoniae } \\
\text { pneumonia }(0.6 \%)\end{array}$ & $\begin{array}{l}599.0 \text { Urinary tract } \\
\text { infection }(1.5 \%)\end{array}$ & $\begin{array}{c}\text { 414.01 Coronary } \\
\text { atherosclerosis }(1.4 \%)\end{array}$ & $\begin{array}{c}428.33 \text { Acute on chronic } \\
\text { diastolic heart failure }(0.9 \%)\end{array}$ & $\begin{array}{c}\text { 428.0 Congestive heart failure } \\
(1.1 \%)\end{array}$ \\
\hline
\end{tabular}

Diagnoses are given as International Classification of Diseases, Ninth Revision, Clinical Modification codes. ICS: inhaled corticosteroid; COPD: chronic obstructive pulmonary disease (obstructive chronic bronchitis); MRSA: methicillin-resistant Staphylococcus aureus; MSSA: methicillin-sensitive S. aureus. ${ }^{\#}$ : no cause of death available for ICS therapy $\mathrm{n}=1135$ (33.7\%) and macrolide monotherapy $n=85(31.5 \%)$; " : number of outcome events. 


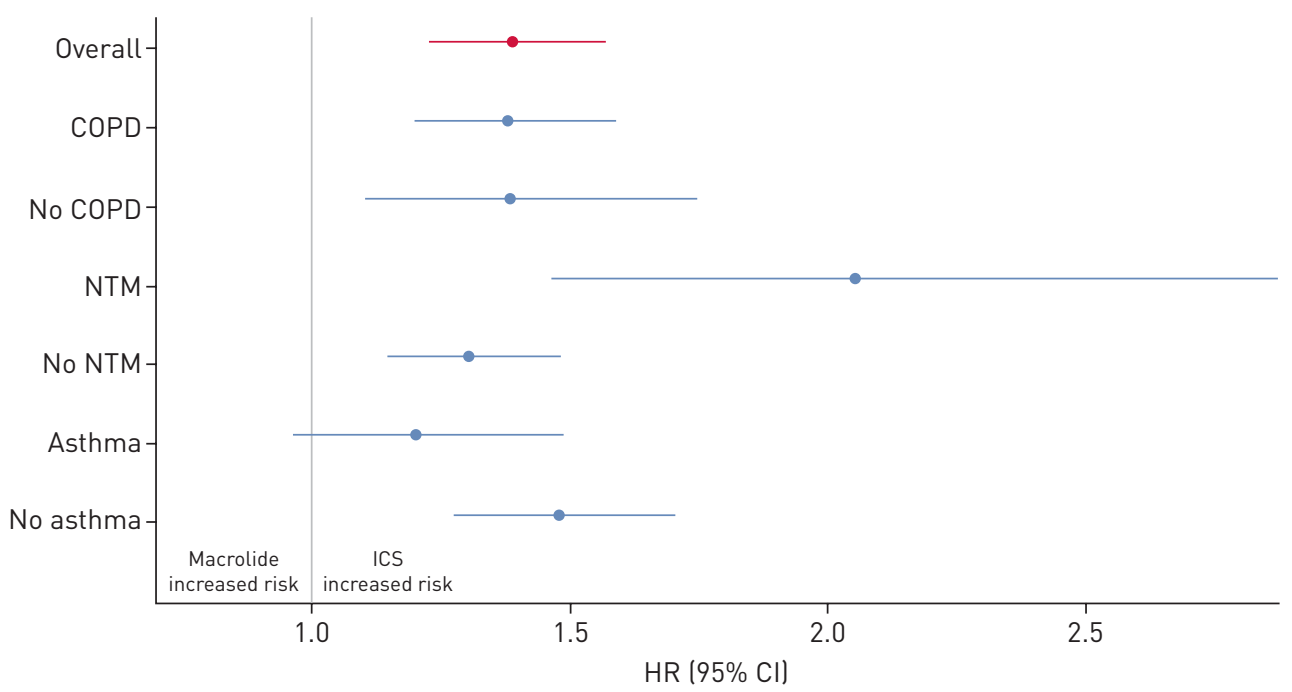

FIGURE 3 Forest plot of adjusted hazard ratios (95\% Cls) of hospitalised respiratory infection comparing new use of inhaled corticosteroid (ICS) therapy to macrolide monotherapy for bronchiectasis: overall (red) and stratified by underlying lung disease (blue). COPD: chronic obstructive pulmonary disease; NTM: nontuberculous mycobacteria. Adjusted hazard ratios included propensity score decile, oral corticosteroid dose category and NTM history.

produced similar hazard ratios for hospitalised respiratory infection in each comparison group (figure 3). Stratification by asthma suggested that patients with an asthma diagnosis taking ICS may have a lower risk of hospitalised respiratory infection: HR comparing ICS versus macrolides 1.00 (95\% CI 0.80-1.25) and adjusted HR 1.20 (95\% CI 0.96-1.49) compared with HR 1.33 (95\% CI 1.2-1.5) and adjusted HR 1.47 (95\% CI 1.27-1.71) in those with no asthma diagnosis ( $\mathrm{p}$-value for interaction $<0.001$ ).

\section{Discussion}

In a Medicare population-based analysis, we found that chronic ICS use was associated with an increased risk of hospitalisation due to respiratory infection compared with macrolide monotherapy in patients with bronchiectasis. Despite a lower rate of prior infections in the ICS cohort compared with the macrolide cohort, e.g. baseline acute respiratory infection and history of Pseudomonas, and similar rates of baseline hospitalised respiratory infections compared with the macrolide cohort, after initiating ICSs patients had a higher relative risk of hospitalisation and death. The direction and magnitude of risk did not change in the subgroup of patients with an underlying COPD diagnosis.

The study cohort is typical of the older population ( $\geqslant 65$ year old) in the USA, which includes $\sim 75 \%$ all bronchiectasis patients, in contrast to Europe where $50 \%$ of all bronchiectasis patients are $\geqslant 65$ years old $[30,31]$. The proportion of female patients in each treatment group (67\% ICS and $73 \%$ macrolide) was higher than reported in the UK (58\%), but similar to the overall population of adults with bronchiectasis in the USA $(67 \%)[2,30]$. Treated patients included in our cohort were on average 1-2 years younger than the overall prevalent bronchiectasis population within Medicare, which is reasonable considering we included patients at "first new use" [32].

There is evidence that ICS therapy reduces exacerbations and slows the decline of quality of life in patients with advanced COPD [33]. To date, however, there is no evidence that long-term use of corticosteroids benefits patients with bronchiectasis and no large clinical trials have looked at ICS use in bronchiectasis. Several small randomised trials in patients with multiple exacerbations in the prior year have suggested an improvement in symptoms in patients receiving ICSs for 6-12 months, but no difference in other outcomes when compared with placebo [34-36]. The systematic review of therapies included in the 2010 British Thoracic Society guidelines and more recent 2017 European Respiratory Society guidelines concluded that there is a lack of evidence to support the chronic use of OCSs or ICSs in bronchiectasis [9, 11]. Despite these recommendations, the use of ICSs among such patients is common in the USA, even in patients without an indication for their use (asthma or COPD diagnoses) [14, 37-39]. Ongoing registry data and our finding that the risk of hospitalised respiratory infections was somewhat decreased in patients with bronchiectasis and an asthma diagnosis may reflect the benefit of appropriate use of ICSs to treat asthma.

There are data in other types of chronic lung disease suggesting that OCS or ICS use increases the risk of infection, particularly pneumonia [40], an outcome for which bronchiectasis patients are already at 
increased risk. In COPD patients, a population-based study identified a rate ratio of 1.69 (95\% CI 1.63 1.75) for serious pneumonia in current ICS users [12]. We observed an attenuated but clinically meaningful 39\% increase in the relative risk of hospitalised respiratory infection which was based on a comparison with another active treatment (macrolide monotherapy). A recent meta-analysis concluded that budesonide and fluticasone, with or without long-acting bronchodilators, are associated with increased risk of serious adverse pneumonia events in COPD patients, but not an increased risk of death [41]. We observed a similar pattern in our population of elderly bronchiectasis patients.

Antibiotics are used with the twin goals of reducing bacterial load in the airways, which in turn reduces airway inflammation, and, in the case of macrolides, exerting an immunomodulatory role independent of bacterial load reduction [15, 42]. Two small randomised clinical trials published in 2012 and 2013 evaluated long-term (6 months to 1 year) azithromycin and a third evaluated long-term erythromycin use in bronchiectasis patients [16-18]. While macrolide-treated groups experienced fewer respiratory exacerbations, defined as increasing symptoms (requiring treatment in two studies), there was limited or no improvement in overall lung function. Treatment guidelines have recommended that macrolides be considered for the subset of patients with a history of repeated exacerbations. For example, the 2017 European Respiratory Society guidelines suggest considering macrolides in patients with three or more exacerbations, either in the absence of $P$. aeruginosa infection or in those with $P$. aeruginosa infection in whom inhaled antibiotics are not efficacious or not tolerated [11]. In contrast to ICSs, we observed relatively low rates of chronic macrolide use in Medicare patients through 2014, similar to what was observed in the US Bronchiectasis and NTM Research Registry [39]. These rates may reflect the high rates of NTM isolation in the registry and may have increased after 2014 as time allows for practice change after the publication of the 2012/2013 randomised clinical trials.

Our results suggest that macrolides are associated with lower risks of common outcomes of treated acute infectious exacerbations and serious outcomes of hospitalised respiratory infection compared with ICSs. In general, the risks of antibiotic therapy compared with benefits are not clear. Azithromycin use has been linked to sudden cardiac death in population-based studies [43] and it is known to cause QT prolongation with potential for causing other cardiac arrhythmias, particularly when used with other drugs that also cause QT prolongation [44]. Furthermore, a significant risk of long-term azithromycin use could be the selection of macrolide-resistant NTM in patients with NTM isolated in respiratory specimens. Accordingly, macrolide monotherapy is not to be used in the treatment of pulmonary NTM disease (similar to tuberculosis where multiple drugs are used to diminish the evolution of drug resistance) [45]. The top 10 causes of hospitalisation or death within 30 days of discharge in our study population were similar between the two treatment cohorts, predominately related to respiratory failure and notably not cardiac arrest in either cohort.

Most therapies for bronchiectasis have received little research attention outside of CF populations, meaning the proposed benefits/risks of their use have been extrapolated from these and other settings of chronic lung disease such as COPD. However, the pathophysiology and natural history of bronchiectasis is distinct from CF-associated bronchiectasis and other lung diseases, and therapies that benefit one do not necessarily benefit the other. For example, DNase, which improves mucus clearance and outcomes in CF bronchiectasis patients, actually caused worsened lung function in other bronchiectasis patients [46, 47]. This underscores the importance of evaluating therapies within diverse populations of patients with bronchiectasis, rather than extrapolating from studies performed in other chronic lung disease conditions or bronchiectasis associated with CF.

Strengths of the study include the fact that it is a real-world, large population-based evaluation of the comparative risks of ICS therapy and macrolide monotherapy use in older bronchiectasis patients. Although older bronchiectasis patients tend to have more comorbidities, at least one study has shown that the aetiology and severity of bronchiectasis do not differ across age groups, except that the proportion of bronchiectasis due to COPD increased with age [31]. Our analysis used established new-user methodology, PS adjustment, an active control group and was limited to the first event of interest to account for channelling bias that otherwise limits our ability to determine causal association in observational studies. Although there were significant differences between the two exposure groups at treatment start, the proportion of COPD or Pseudomonas diagnoses was well balanced within each PS decile.

The main limitations result from the use of claims-based data, which limited our ability to confirm the bronchiectasis diagnosis and include disease symptoms or severity in our models and acute exacerbation definition. Although the PS balances the cohorts across known characteristics, there are likely additional (unmeasured) factors that influence treatment decisions. We were able to balance for important risk factors for hospitalisation and death of bronchiectasis patients, including acute respiratory infection history and comorbidities, in addition to utilisation history. There is the possibility of a small amount of residual 
confounding, given the slightly elevated risk in nonrespiratory infection hospitalisations, although that risk was predominantly driven by COPD exacerbations and other underlying lung disease. Furthermore, the Medicare study population consists of adults aged $\geqslant 65$ years and results may not be applicable to younger bronchiectasis patients who have a different comorbidity profile [31]. There may be additional limitations extrapolating to other healthcare systems.

Our results provide evidence that the widespread use of chronic ICSs in older bronchiectasis patients without comorbid indications such as asthma and COPD is not supported. Future studies using registry or electronic health record data may be able to better group patients by comorbidities that impact therapy choice and include younger patients. Macrolides may be a better choice than ICSs to prevent hospitalised respiratory infections and acute respiratory infections in older bronchiectasis patients with frequent exacerbations. Further study of potential long-term risks and benefits of macrolide monotherapy is recommended.

Acknowledgements: The authors would like to recognise the contributions of Megan Wardrop at OHSU-PSU School of Public Health (Portland, OR, USA), key stakeholders from the project's Patient Advisory Panel, Alexandra Quittner at Nicklaus Children's Health Institute (Miami, FL, USA), Elisha Malanga, Delia Prieto and Gretchen McCreary at the COPD Foundation (Washington, DC, USA), and Amy Leitman at NTM Info and Research (Coral Gables, FL, USA).

Author contributions: E. Henkle had full access to all of the data in the study, and takes responsibility for the integrity of the data and the accuracy of the data analysis. E. Henkle drafted the manuscript. All other co-authors contributed substantially to the study design, data analysis and interpretation, and the writing of the manuscript.

Conflict of interest: E. Henkle has nothing to disclose. J.R. Curtis has nothing to disclose. L. Chen has nothing to disclose. B. Chan has nothing to disclose. T.R. Aksamit has nothing to disclose. C.L. Daley reports grants from Insmed, outside the submitted work. D.E. Griffith has nothing to disclose. K.L. Winthrop reports personal fees for consultancy from Bayer, outside the submitted work.

Support statement: Research reported in this manuscript was funded through a Patient-Centered Outcomes Research Institute (PCORI) Award (CER-1503-29191). The statements and conclusions in this manuscript are solely the responsibility of the authors and do not necessarily represent the views of the PCORI, its Board of Governors or Methodology Committee. Funding information for this article has been deposited with the Crossref Funder Registry.

\section{References}

1 Seitz AE, Olivier KN, Adjemian J, et al. Trends in bronchiectasis among Medicare beneficiaries in the United States, 2000 to 2007. Chest 2012; 142: 432-439.

2 Quint JK, Millett ER, Joshi M, et al. Changes in the incidence, prevalence and mortality of bronchiectasis in the UK from 2004 to 2013: a population-based cohort study. Eur Respir J 2016; 47: 186-193. O'Donnell AE. Bronchiectasis. Chest 2008; 134: 815-823.

4 McShane PJ, Naureckas ET, Tino G, et al. Non-cystic fibrosis bronchiectasis. Am J Respir Crit Care Med 2013; 188: 647-656.

5 Aliberti S, Lonni S, Dore S, et al. Clinical phenotypes in adult patients with bronchiectasis. Eur Respir J 2016; 47: 1113-1122.

6 McDonnell MJ, Aliberti S, Goeminne PC, et al. Comorbidities and the risk of mortality in patients with bronchiectasis: an international multicentre cohort study. Lancet Respir Med 2016; 4: 969-979.

7 De Soyza A, McDonnell MJ, Goeminne PC, et al. Bronchiectasis rheumatoid overlap syndrome is an independent risk factor for mortality in patients with bronchiectasis: a multicenter cohort study. Chest 2017; 151: 1247-1254.

8 Chalmers JD, Aliberti S, Filonenko A, et al. Characterisation of the "frequent exacerbator phenotype" in bronchiectasis. Am J Respir Crit Care Med 2018; 197: 1410-1420.

9 Pasteur MC, Bilton D, Hill AT. British Thoracic Society guideline for non-CF bronchiectasis. Thorax 2010; 65: Suppl. 1, i1-i58.

10 Martinez-Garcia MA, Maiz L, Olveira C, et al. Spanish guidelines on treatment of bronchiectasis in adults. Arch Bronconeumol 2018; 54: 88-98.

11 Polverino E, Goeminne PC, McDonnell MJ, et al. European Respiratory Society guidelines for the management of adult bronchiectasis. Eur Respir J 2017; 50: 1700629.

12 Suissa S, Patenaude V, Lapi F, et al. Inhaled corticosteroids in COPD and the risk of serious pneumonia. Thorax 2013; 68: 1029-1036.

13 Andrejak C, Nielsen R, Thomsen VO, et al. Chronic respiratory disease, inhaled corticosteroids and risk of non-tuberculous mycobacteriosis. Thorax 2013; 68: 256-262.

14 Henkle E, Aksamit TR, Barker AF, et al. Pharmacotherapy for non-cystic fibrosis bronchiectasis: results from an NTM Info \& Research Patient Survey and the Bronchiectasis and NTM Research Registry. Chest 2017; 152: $1120-1127$.

15 Kanoh S, Rubin BK. Mechanisms of action and clinical application of macrolides as immunomodulatory medications. Clin Microbiol Rev 2010; 23: 590-615.

16 Altenburg J, de Graaff CS, Stienstra Y, et al. Effect of azithromycin maintenance treatment on infectious exacerbations among patients with non-cystic fibrosis bronchiectasis: the BAT randomized controlled trial. JAMA 2013; 309: 1251-1259.

17 Serisier DJ, Martin ML, McGuckin MA, et al. Effect of long-term, low-dose erythromycin on pulmonary exacerbations among patients with non-cystic fibrosis bronchiectasis: the BLESS randomized controlled trial. JAMA 2013; 309: 1260-1267. 
18 Wong C, Jayaram L, Karalus N, et al. Azithromycin for prevention of exacerbations in non-cystic fibrosis bronchiectasis (EMBRACE): a randomised, double-blind, placebo-controlled trial. Lancet 2012; 380: 660-667.

19 Ray WA. Evaluating medication effects outside of clinical trials: new-user designs. Am J Epidemiol 2003; 158: 915-920.

20 Seitz AE, Olivier KN, Adjemian J, et al. Trends in bronchiectasis among Medicare beneficiaries in the United States, 2000 to 2007. Chest 2012; 142: 432-439.

21 Seitz AE, Olivier KN, Steiner CA, et al. Trends and burden of bronchiectasis-associated hospitalizations in the United States, 1993-2006. Chest 2010; 138: 944-949.

22 Grijalva CG, Chen L, Delzell E, et al. Initiation of tumor necrosis factor-alpha antagonists and the risk of hospitalization for infection in patients with autoimmune diseases. JAMA 2011; 306: 2331-2339.

23 Herrinton LJ, Curtis JR, Chen L, et al. Study design for a comprehensive assessment of biologic safety using multiple healthcare data systems. Pharmacoepidemiol Drug Saf 2011; 20: 1199-1209.

24 Winthrop KL, Baddley JW, Chen L, et al. Association between the initiation of anti-tumor necrosis factor therapy and the risk of herpes zoster. JAMA 2013; 309: 887-895.

25 Jackson LA, Neuzil KM, Yu O, et al. Effectiveness of pneumococcal polysaccharide vaccine in older adults. $N$ Engl J Med 2003; 348: 1747-1755.

26 Grijalva CG, Chung CP, Stein CM, et al. Computerized definitions showed high positive predictive values for identifying hospitalizations for congestive heart failure and selected infections in Medicaid enrollees with rheumatoid arthritis. Pharmacoepidemiol Drug Saf 2008; 17: 890-895.

27 Sullivan GM, Feinn R. Using effect size - or why the P value is not enough. J Grad Med Educ 2012; 4: $279-282$.

28 D'Agostino RB Jr. Propensity score methods for bias reduction in the comparison of a treatment to a non-randomized control group. Stat Med 1998; 17: 2265-2281.

29 Cox D. Regression models and life tables (with discussion). J Royal Stat Soc Ser B 1972; 34: 187-220.

30 Weycker D, Hansen GL, Seifer FD. Prevalence and incidence of noncystic fibrosis bronchiectasis among US adults in 2013. Chron Respir Dis 2017; 14: 377-384.

31 Bellelli G, Chalmers JD, Sotgiu G, et al. Characterization of bronchiectasis in the elderly. Respir Med 2016; 119: 13-19.

32 Henkle E, Chan B, Curtis JR, et al. Characteristics and health-care utilization history of patients with bronchiectasis in US Medicare enrollees with prescription drug plans, 2006 to 2014. Chest 2018; 154: 1311-1320.

33 Kew KM, Dias S, Cates CJ. Long-acting inhaled therapy (beta-agonists, anticholinergics and steroids) for COPD: a network meta-analysis. Cochrane Database Syst Rev 2014; 3: CD010844.

34 Hernando R, Drobnic ME, Cruz MJ, et al. Budesonide efficacy and safety in patients with bronchiectasis not due to cystic fibrosis. Int J Clin Pharm 2012; 34: 644-650.

35 Martinez-Garcia MA, Perpina-Tordera M, Roman-Sanchez P, et al. Inhaled steroids improve quality of life in patients with steady-state bronchiectasis. Respir Med 2006; 100: 1623-1632.

36 Tsang KW, Tan KC, Ho PL, et al. Inhaled fluticasone in bronchiectasis: a 12 month study. Thorax 2005; 60: 239-243.

37 Felson DT, LaValley MP. The ACR20 and defining a threshold for response in rheumatic diseases: too much of a good thing. Arthritis Res Ther 2014; 16: 101.

38 Ryu YJ, Kim EJ, Lee SH, et al. Impaired expression of Toll-like receptor 2 in nontuberculous mycobacterial lung disease. Eur Respir J 2007; 30: 736-742.

39 Aksamit TR, O’Donnell AE, Barker A, et al. Adult patients with bronchiectasis: a first look at the US Bronchiectasis Research Registry. Chest 2017; 151: 982-992.

40 Drummond MB, Dasenbrook EC, Pitz MW, et al. Inhaled corticosteroids in patients with stable chronic obstructive pulmonary disease: a systematic review and meta-analysis. JAMA 2008; 300: 2407-2416.

41 Kew KM, Seniukovich A. Inhaled steroids and risk of pneumonia for chronic obstructive pulmonary disease. Cochrane Database Syst Rev 2014; 3: CD010115.

42 Chalmers JD, Smith MP, McHugh BJ, et al. Short- and long-term antibiotic treatment reduces airway and systemic inflammation in non-cystic fibrosis bronchiectasis. Am J Respir Crit Care Med 2012; 186: 657-665.

43 Ray WA, Murray KT, Hall K, et al. Azithromycin and the risk of cardiovascular death. N Engl J Med 2012; 366: $1881-1890$.

44 Zareba W. Drug induced QT prolongation. Cardiol J 2007; 14: 523-533.

45 Griffith DE, Aksamit T, Brown-Elliott BA, et al. An official ATS/IDSA statement: diagnosis, treatment, and prevention of nontuberculous mycobacterial diseases. Am J Respir Crit Care Med 2007; 175: 367-416.

46 O'Donnell AE, Barker AF, Ilowite JS, et al. Treatment of idiopathic bronchiectasis with aerosolized recombinant human DNase I. rhDNase Study Group. Chest 1998; 113: 1329-1334.

47 Wills PJ, Wodehouse T, Corkery K, et al. Short-term recombinant human DNase in bronchiectasis. Effect on clinical state and in vitro sputum transportability. Am J Respir Crit Care Med 1996; 154: 413-417. 